\title{
Recursos Educativos Abiertos, una alternativa para apoyar la comprensión lectora en el grado primero
}

Recibido: 15 Ago 2016 - Revisado: 30 Sep 2016 Aceptado: 30 Oct 2016 - Publicado: 30 Dic 2016

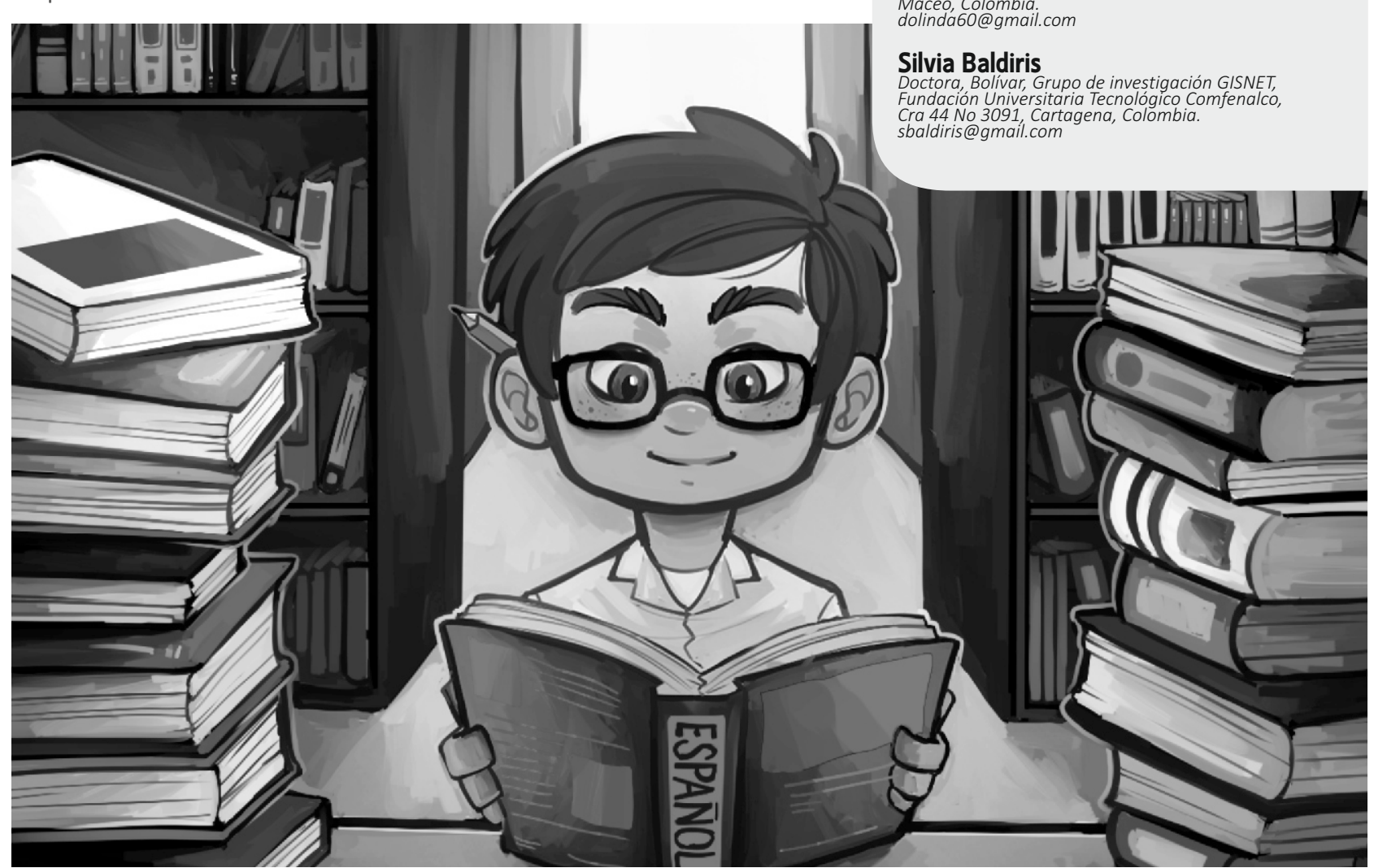

Resumen: En este artículo se presenta una aproximación basada en el uso adecuado de las TAC como apoyo al logro del nivel intratextual de la comprensión lectora, en el área de lenguaje del grado primero en las Instituciones Educativas Hermano Daniel y Filiberto Restrepo Sierra (municipios de Puerto Triunfo y Maceo) en Antioquia, a partir de la implementación de Recursos Educativos Abiertos (REA). Estos REA se desarrollan de forma didáctica e interactiva para decodificar el espectacular mundo de las letras y apoyar el desarrollo de las competencias comunicativas en los infantes. Los REA construidos fueron validados en el ambiente real con los estudiantes del grado primero A de ambas instituciones y se obtuvieron resultados significativos.

Palabras clave: comprensión; Intratextual; multimedia; TAC; REA.

Abstract: In this article an approach based on the appropriate use of ACT to support the achievement of intratextual level of reading comprehension in the language area of the first degree in Educational Institutions Brother presents Daniel (home Florida) and Filiberto Restrepo Sierra (municipalities of Puerto Triunfo and Maceo) in Antioquia, from the implementation of Open Educational Resources (OER). These REA develop a didactic and interactive to decode the spectacular world of letters and support the development of communication skills in infants. The built REA were validated in the real environment with first grade students " $A$ " of both institutions obtaining meaningful results.

Key words: comprehension; intratextual; multimedia; ACT; OER. 


\section{INTRODUCCIÓN}

En el grado primero de las Instituciones Educativas Hermano Daniel y Filiberto Restrepo Sierra (municipios de Puerto Triunfo y Maceo), en Antioquia, se observa que los estudiantes presentan dificultades en los procesos de enseñanza/aprendizaje; se hacen notorias las altas tasas de reprobación escolar, debido a dificultades de aprendizaje, falta de motivación, inadecuada metodología docente y/o poco acompañamiento familiar.

El grado Primero A presenta dificultades para leer e interpretar información gráfica y textual. Estas son ocasionadas por la inadecuada metodología que causa falta de motivación en el aula.

Es difícil motivar a los niños a aprender si el material que deben leer y escribir, escuchar y decir no tiene relación con lo que ellos piensan y hacen (Caamaño \& González, 2012).

Muchos autores concuerdan en que el elemento clave no es el medio utilizado, ya sea este el video o un ordenador; realmente el elemento clave es la metodología utilizada por el profesor, la dinámica que es capaz de llevar a su clase (Aliaga y Bartolomé 2006). En este artículo, presentamos una aproximación para apoyar el desarrollo del nivel intratextual de la comprensión lectora en el grado primero, aprovechando las potencialidades de las TAC para facilitar los aprendizajes de los estudiantes, en particular, a través de la creación de Recursos Educativos Abiertos (REA) (UNESCO 2015), que afianzan la competencia lectora desde la significación. Los REA desarrollados se conciben como una alternativa para recuperar información explícita y apoyar el nivel intratextual de aprendizaje de la comprensión lectora en el grado primero, a partir de la semántica y la sintaxis en microestructuras.

En concreto, se implementaron los REA LIM del abecedario 2.0 y Test de comprensión literal 2.0 en el grado Primero A. Los REA LIM del abecedario 2.0 afianzan la competencia lectora en los diversos ritmos de aprendizaje. Por su parte los REA Test de comprensión literal 2.0 evalúan la comprensión lectora en el nivel literal.

Desarrollados los recursos, se diseñó un experimento para la validación de los mismos, definiendo el desempeño de los estudiantes como variable a describir.

Los resultados del proceso de validación son llevados a cabo con 24 estudiantes de la I. E. R. Hermano Daniel (HD) y 30 estudiantes de la I. E. Filiberto Restrepo Sierra (FRS). Estos fueron alentadores e indicativos de la facilicidad de uso de los REA y de la utilidad de los mismos para el logro del propósito con el que fueron creados.

El artículo está organizado de la siguiente manera: en la sección dos, presentamos la revisión de literatura que soporta este trabajo; en la sección tres, describimos la selección de tecnologías para la implementación de los REA; en la sección cuatro, presentamos el proceso de creación de los REA, para apoyar el nivel intratextual de aprendizaje de la comprensión lectora en el grado primero; en la sección cinco, presentamos la fase de implementación y evaluación de los REA; y en la sección seis, presentamos las conclusiones y trabajos futuros.

\section{REVISIÓN DE LITERATURA}

En el ámbito nacional colombiano, se evidencia que las TIC se usan como facilitadoras en la comprensión lectora (Hernández y Arteaga 2011). En su estudio buscaron demostrar el impacto de las TIC en las etapas de anticipación e inferencia de la comprensión lectora y la importancia que tiene el docente en los procesos educativos, como mediador de la enseñanza. 
Los resultados demostraron que los educandos seleccionados para esta intervención, manifestaron interés y curiosidad por explorar la herramienta, lo cual demuestra, al igual que sus respuestas, tanto en el aspecto anticipatorio como de inferencia, que los procesos de comprensión lectora apoyados en las TIC son de utilidad (Hernández y Arteaga 2011).

Asimismo, se evidenció que cada estudiante tuvo su propio ritmo de aprendizaje, por tal razón, fue primordial identificar las necesidades de cada uno de ellos para orientarlos en sus competencias individuales y así posibilitarles avanzar satisfactoriamente en su proceso de aprendizaje.

En el ámbito local, se implementó en la ciudad de Medellín, Antioquia, Colombia, el estudio Comprensión lectora en el niño, cuestión de ingenio (Tabares, Garcés y Gómez 2013). En dicha investigación, buscaron implementar y analizar una estrategia que favorezca el desarrollo de los niveles literal e inferencial, mediada por las TIC en un proceso de trabajo colaborativo.

La estrategia didáctica de esta investigación fue la ejecución de un noticiero y la prensa donde los estudiantes cumplieron roles como presentadores y corresponsales de noticias, para afianzar su nivel literal e inferencial: desde allí, los niños formaron equipos de trabajo y espontáneamente a partir de sus saberes previos cumplieron con el rol asignado. Esto generó en los estudiantes, experiencias significativas de aprendizaje, donde afianzaron sus capacidades intelectuales y mejoraron los niveles de comprensión lectora, posibilitándoles autonomía para buscar, crear y transmitir información.

Las investigaciones presentadas muestran la importancia de fortalecer los procesos de comprensión lectora, con estrategias didácticas que sean del interés y motivación para los educandos, permitiéndoles aprender, inventar y transformar lo que perciben de su entorno, para que interpreten el contexto sociocultural y comuniquen todos sus conocimientos, a través de diferentes representaciones comunicativas como lo son palabras, gestos, acciones, códigos y símbolos.

\section{TECNOLOGÍAS PARA LA IMPLEMENTACIÓN DE LOS REA}

Paredes (2013) introduce el término TAC como Tecnologías del Aprendizaje y del Conocimiento, es decir, tecnologías con una finalidad educativa significativa, acompañada de metodologías que apoyan y favorecen los procesos de aprendizaje.

Se ha demostrado que el aprendizaje apoyado por las TAC trae grandes beneficios para los estudiantes poco motivados o con necesidades educativas diversas, ya que este tipo de tecnologías optimizan los procesos educativos; lo que no solo se traduce en mejores resultados académicos, sino también de integración escolar, ya que la flexibilidad de estas tecnologías apoya la generación de estrategias didácticas que se adaptan a los estilos y ritmos de aprendizaje individuales.

Los Libros Interactivos Multimedia (LIM) pueden ser considerados TAC, se utilizan para potenciar las habilidades comunicativas (hablar, leer, escribir y escuchar) y competencias comunicativas (lectora y escritora). Martínez y Alonso (2014) concluyen que a través de la composición de archivos de texto y audiovisuales en el LIM es posible optimizar la comprensión lectora y auditiva de los alumnos.

EdiLIM es uno de los editores de LIM más validados y conocidos en el ámbito internacional.

Por otra parte, App Inventor 2 facilita a los docentes la creación de aplicaciones básicas. Con esta herramienta los profesores pueden generar una gran cantidad de aplicaciones para Android, ya que no es necesario tener un conocimiento avanzado de programación (Londoño 2011). 
Estas dos tecnologías fueron seleccionadas a partir de la revisión de literatura para diseñar los REA de esta investigación. Estas dos tecnologías se analizaron con diferentes factores que permitieron visualizar implícitamente los criterios de usabilidad, gratuidad y viabilidad de implementación en el aula de clase. La información anterior se describe en la Tabla 1

Tabla 1 . Características de los software seleccionados.

\begin{tabular}{|c|c|c|}
\hline Característica & EdiLIM & App Inventor 2 \\
\hline Creador & Fran Macías & Google \\
\hline Idiomas & 12 & 6 \\
\hline $\begin{array}{l}\text { Versión } \\
\text { actual }\end{array}$ & 4.1 & 2.0 \\
\hline Carácter & Gratuito & Gratuito \\
\hline Producto & $\begin{array}{l}\text { Libros } \\
\text { Interactivos } \\
\text { Multimedia (LIM) } \\
\text { online y offline }\end{array}$ & $\begin{array}{l}\text { Aplicaciones } \\
\text { móviles sin } \\
\text { conexión a } \\
\text { Internet (offline) }\end{array}$ \\
\hline $\begin{array}{l}\text { Dirigido a } \\
\text { dispositivos }\end{array}$ & $\begin{array}{l}\text { Dispositivos fijos } \\
\text { (computadores) }\end{array}$ & $\begin{array}{l}\text { Dispositivos } \\
\text { móviles } \\
\text { (Smartphone o } \\
\text { tablet con } \\
\text { Android) }\end{array}$ \\
\hline $\begin{array}{l}\text { Compatible } \\
\text { para } \\
\text { desarrollar en }\end{array}$ & $\begin{array}{l}\text { Windows, Linux y } \\
\text { Mac }\end{array}$ & $\begin{array}{l}\text { Windows, Linux y } \\
\text { Mac }\end{array}$ \\
\hline Diseña & $\begin{array}{l}\text { Material } \\
\text { educativo en LIM }\end{array}$ & $\begin{array}{l}\text { Aplicaciones de } \\
\text { entretenimiento, } \\
\text { funcionamiento, } \\
\text { comercio y } \\
\text { aprendizaje. }\end{array}$ \\
\hline $\begin{array}{l}\text { Ejecutable } \\
\text { para } \\
\text { desarrollar }\end{array}$ & En PC (offline) & $\begin{array}{l}\text { Desde la web } \\
\text { (online) }\end{array}$ \\
\hline $\begin{array}{l}\text { Instalación } \\
\text { del software }\end{array}$ & No requiere & No requiere \\
\hline Reproductor & $\begin{array}{l}\text { Cualquier } \\
\text { navegador de } \\
\text { Internet }\end{array}$ & $\begin{array}{l}\text { Dispositivos } \\
\text { móviles con } \\
\text { Android }\end{array}$ \\
\hline Publicación & sitios web & $\begin{array}{l}\text { Sitios web y } \\
\text { Google Play }\end{array}$ \\
\hline $\begin{array}{l}\text { Entorno de } \\
\text { aprendizaje }\end{array}$ & Básico y llamativo & Personalizado \\
\hline $\begin{array}{l}\text { Manipulación } \\
\text { en el } \\
\text { dispositivo }\end{array}$ & $\begin{array}{l}\text { touch o mouse } \\
\text { del computador }\end{array}$ & $\begin{array}{l}\text { Pantalla táctil del } \\
\text { dispositivo móvil }\end{array}$ \\
\hline
\end{tabular}

\begin{tabular}{|lll|}
\hline Páginas & 51 estilos & Personalizadas \\
& Entornos & Gran variedad de \\
atractivos, fácil & funciones y \\
& uso, usa recursos & posibilidades, usa \\
& multimedia, & diversos recursos. \\
& permite conocer & \\
& el rendimiento & \\
& del usuario, & Dominar todas sus \\
& retroalimentación & características o \\
& y es portable. & funciones no \\
& No hay forma de & resulta sencillo. \\
Desventajas & personalizar el & \\
& entorno de cada & \\
& página y en & \\
& algunos casos & \\
& tienen una & \\
& extensión & \\
& limitada de & \\
& caracteres. & \\
& &
\end{tabular}

\section{PROCESOS DE CREACIÓN DE LOS REA PARA APOYAR EL NIVEL INTRATEXTUAL DE APRENDIZAJE DE LA COMPRENSIÓN LECTORA EN EL GRADO PRIMERO}

En el proceso de creación de los REA para apoyar el nivel intratextual de aprendizaje de la comprensión lectora en el grado primero, se llevaron a cabo los siguientes pasos o fases: (a) Identificación de las necesidades de la población objeto de estudio y (b) Fase de diseño y desarrollo de los REA.

(a) Identificación de las necesidades de la población de estudio: Para analizar las características y las necesidades educativas de la población objeto, se recolectaron datos a partir de tres encuestas tipo Likert (demográfica, apoyo familiar en el área de lenguaje, uso de dispositivos móviles e internet) aplicadas a los padres de familia. Adicionalmente se creó el perfil del curso, a partir del instrumento propuesto por el Diseño Universal para el Aprendizaje (DUA) (Pastor 2012).

En la encuesta demográfica, se concluye que existen varios factores externos (escolaridad de los padres de 
familia, núcleo familiar y situación económica,) e internos (discapacidad visual o cognitiva, ritmo de aprendizaje), que influyen en el aprendizaje de los educandos, los cuales, deben ser identificados y orientados contando con el apoyo del docente y el acompañamiento familiar.

En la encuesta apoyo familiar en el área de lenguaje, se concluye con la información recolectada, que las familias usan las tecnologías para fines personales, al igual que cada hogar cuenta con mínimo un dispositivo tecnológico (computador, celular inteligente o tablet), donde más de la mitad usa frecuentemente estos dispositivos y tienen acceso a internet. De la misma manera, las familias en su mayoría manifiestan tener disposición para que sus hijos aprendan usando las tecnologías a las que tienen acceso.

En la encuesta Uso de dispositivos móviles e internet, se concluye que hay actividades que los padres de familia no hacen respecto a la formación de los educandos y que pueden beneficiar el desempeño de sus hijos en el área de lenguaje.

Para terminar esta fase, se utilizó el instrumento perfil del curso, con el propósito de identificar las debilidades, fortalezas y preferencias de los estudiantes que influyen en la lectura y la comprensión lectora.

El perfil del curso es una caracterización de la población de estudio para la atención a la diversidad en el aula. Para el desarrollo, se empleó el instrumento mostrado en la Tabla 2, propuesta del DUA, el cual propone unos principios basados en conceptos que provienen de la neurociencia y la psicología cognitiva, los resultados de las investigaciones sobre el cerebro y las aportaciones de las tecnologías; todo esto, para ofrecer múltiples medios de representación, de acción, expresión y de implicación que garanticen una educación accesible a todos los estudiantes (Pastor 2012).
Con la información recopilada en la tabla 2, se direccionan las fortalezas encontradas de algunos estudiantes para apoyar la comprensión lectora entre pares, por ejemplo: si un niño posee habilidades de lectura avanzada, puede apoyar a los compañeros que presentan dificultades en su vocabulario.

La información sirvió para establecer que era necesario desarrollar REA accesibles a la población de estudio, permitiendo el disfrute y aprendizaje colaborativo de todos los estudiantes, a través de la interacción con las tecnologías en el aula.

El perfil del curso definido fue tenido en cuenta para el diseño y desarrollo de los REA, lo que nos dio pautas para usar correctamente las tecnologías.

Tabla 2. Instrumento perfil del curso

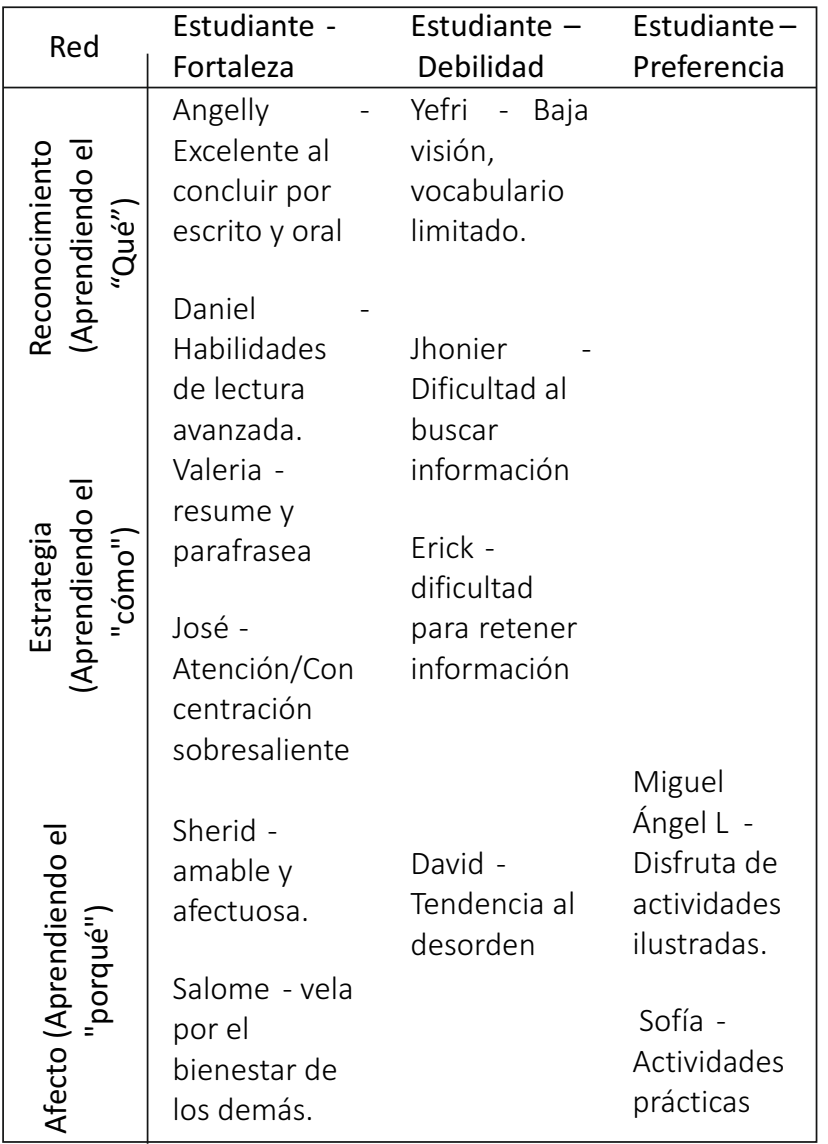


(b) Fase de diseño y desarrollo de los REA: A continuación se describen las características de los productos diseñados haciendo uso de las tecnologías seleccionadas.

\section{(c) LIM del abecedario 2.0.}

El primer producto de esta investigación son los Libros Interactivos Multimedia "LIM del abecedario 2.0", que se usan como estrategia lúdica para interactuar con textos, imágenes, sonidos, palabras y videos en el computador, de ahí el origen de su nombre. Se trata de un libro interactivo multimedia, utilizado por el docente como material pedagógico, que permite ser personalizado a las características propias de cada aula, atendiendo las necesidades educativas de sus alumnos (Martínez y Alonso 2014).

Desde el punto de vista educativo, el LIM del abecedario 2.0 ofrece al estudiante y al docente, un entorno agradable de fácil uso con actividades atractivas, posibilidad de control de progreso, evaluación de los ejercicios, que no require preparación de ordenadores. En definitiva es un recurso fácil de manejar y un entorno de creación de actividades de forma sencilla (Macías 2006).

En la figura 1 se observan los estilos de las actividades de construcción de conocimiento y recepción de información del LIM de la letra G del abecedario 2.0.

La propuesta didáctica sobre la que se basa cada uno de los LIM es el método ecléctico para el proceso de enseñanza aprendizaje de la competencia lectora y la comprensión literal, que toma lo valioso del método sintético y del método global.

En otras palabras, el método ecléctico combina lo mejor de ambos métodos para diseñar una metodología más compleja, es decir, amplía el rango de aprendizaje a partir de sílabas, palabras, frases y textos en contexto, con coherencia, cohesión y significación, es decir, desde la semántica y la sintaxis.

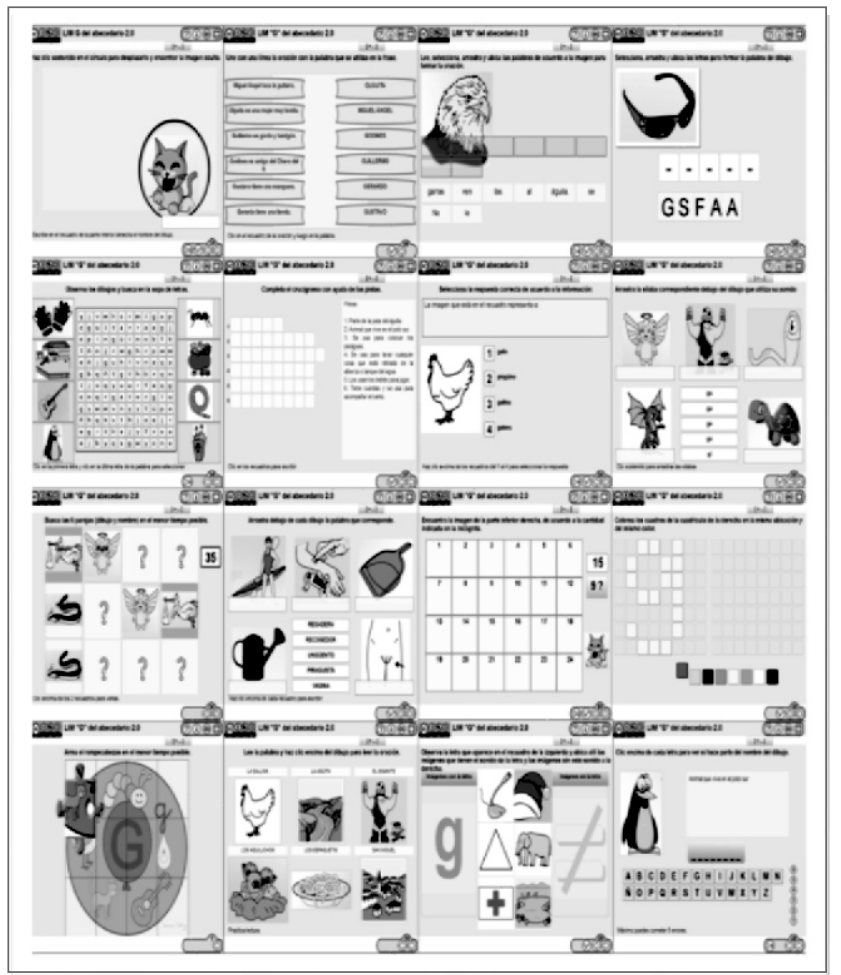

Figura 1. Estilos de actividades LIM G del abecedario 2.0.

Según Piaget, hay cuatro factores que inciden e intervienen en la modificación de estructuras cognoscitivas: la maduración, la experiencia, el equilibrio y la transmisión social. Todos ellos se pueden propiciar a través de ambientes colaborativos (citado por Calzadilla 2002).

En la teoría constructivista (Vigotsky 1974), el aprendizaje requiere la acción de un agente mediador para acceder a la zona de desarrollo próximo, este será responsable de ir teniendo un andamiaje que proporcione seguridad y permita que aquél se apropie del conocimiento y lo transfiera a su propio entorno (Calzadilla 2002). Se concluye que el aprendizaje colaborativo es un proceso de socio construcción, que si es bien aplicado en el aula es enriquecedor para los educandos que tienen dificultades, al igual que para los estudiantes que comparten sus conocimientos. 
A través del uso del LIM del abecedario 2.0 se pretende afianzar el nivel de competencia y comprensión lectora que adquiere el educando con el uso de los LIM, promoviendo un aprendizaje participativo y colaborativo, el cual ubica a los estudiantes en construcción de conocimiento, para trabajar en equipo, donde ellos comparten los saberes con sus pares.

En esta investigación se seleccionaron seis grafías del abecedario, las cuales presentan mayor dificultad fonética o gráfica en la población objeto: $Q, G, \tilde{N}, Y, K$ y $X$.

Los LIM del abecedario 2.0 giran alrededor de estas grafías y su implementación tiene en promedio 96 páginas, todas organizadas aleatoriamente a partir de la segunda actividad, ya que la primera es un test visual mediante la construcción de un rompecabezas asociado al grafema con imágenes en una mándala.

Durante el diseño de los LIM del abecedario 2.0, se estructuraron y unificaron las características de las actividades interactivas, escogiendo 15 estilos de actividades interactivas: rompecabezas, simetría de letras, clasificación de imágenes y letras, ubicar sílabas o palabras parejas, memoria, sopa de letras, preguntas de selección múltiple, lectura de palabras, imágenes y frases, ahorcado, crucigrama, ordena palabras, ordena frases, relación de frases con palabras y rayos $\mathrm{X}$.

(i) Test de comprensión literal 2.0.

Al analizar el contexto de la población objeto, se concluye que ofrecer a los estudiantes textos cortos a partir de microestructuras, con significación y empleando en su mayoría vocabulario de la región podría beneficiar la comprensión lectora en los mismos.

Posteriormente a la lectura de estos textos cortos, se ofrece a los estudiantes un test de comprensión lectora con 10 preguntas de comprensión literal, es decir, el estudiante lee un texto y resuelve las 10 preguntas recuperando información explícita.

Por esta razón, el segundo producto de esta investigación son los test de comprensión literal 2.0 desarrollados con App Inventor 2; que hacen uso de las grandes potencialidades educativas de los dispositivos móviles que fomentan, impulsan y favorecen el desarrollo de las competencias básicas (Cantillo, Roura y Sanchez 2012).

A continuación se muestra en la figura 2, la aplicación del test $\mathrm{G}$ de comprensión literal 2.0 y en la parte inferior, su adaptación para computadores en un LIM:

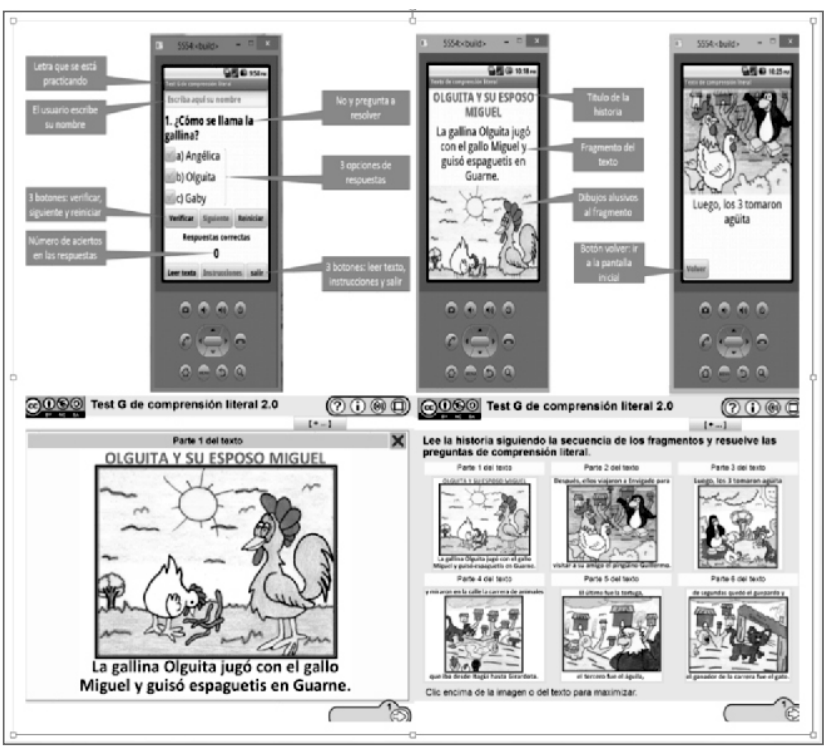

Figura 2. Test $\mathrm{G}$ de comprensión literal 2.0 y su adaptación para PC.

Durante el desarrollo de las aplicaciones Test de comprensión literal, se enfatizó en usar las consonantes seleccionadas $(Q, G, \tilde{N}, Y, K y X)$ en los LIM del abecedario 2.0 y adicionar todas las combinaciones para aprovechar las temáticas del cuarto periodo académico del 2015, ya que son las últimas que se ven en este último periodo.

Es importante resaltar, que el proceso de aprendizaje de las combinaciones es complejo para los educandos 
puesto que se deben asociar dos grafías con una vocal para generar un nuevo sonido, es decir, una combinación, situación que presenta cierto grado de dificultad para ellos porque se les traba la lengua al pronunciarlas. En otras palabras, al afianzar este proceso se fortalece la fluidez verbal y lectora, lo cual es indispensable para leer cualquier texto e interpretarlo.

\section{FASE DE IMPLEMENTACIÓN Y EVALUACIÓN DE LOS REA}

En esta sección se describe la metodología utilizada en el proceso de implementación y evaluación de los REA, así como la descripción de los resultados.

\section{(a) Metodología.}

Se elaboró un trayecto de actividades para el uso de los REA que constó de 13 sesiones. Se ofreció también a los padres de familia y educandos, una capacitación en el uso de las tecnologías y de los REA antes de iniciar el trayectoria de actividades.

Las primeras seis sesiones tuvieron una duración de tres horas y están divididas en tres pasos como se describe a continuación:

En el primer paso, los estudiantes utilizaron los REA de las consonantes $\mathrm{Q}, \mathrm{G}, \tilde{\mathrm{N}}, \mathrm{Y}, \mathrm{K}, \mathrm{X}$ en los computadores. Para ello, se organizó a los educandos en parejas o en tríos (según cantidad de computadores disponibles), a partir de criterios como nivel de lectura, comportamiento e interés, para que los grupos fueran homogéneos y estuvieran en condiciones similares.

Se delegaron funciones de monitor de grupo al estudiante que presentaba mayor liderazgo y trabajo en equipo, el cual fue el encargado de comunicarnos en los momentos en que el grupo presentara dificultades en alguna actividad interactiva; en general, los integrantes del grupo se turnaban y apoyaban para desarrollar las actividades.
En el segundo paso, se realizó una lectura exploratoria con el grupo a partir del título de la historia concreta. Los estudiantes hicieron uso de su imaginación y su creatividad para anticipar el desarrollo y desenlace de la historia e indagar conocimientos previos.

Posteriormente, se entregó una fotocopia con la historia concreta dividida en seis fragmentos secuenciales para que los estudiantes leyeran, constataran y realizaran dibujos alusivos; en otras palabras, los educandos elaboraron la representación gráfica, a partir de la lectura comprensiva de la narración.

En el tercer paso, los estudiantes leyeron la misma historia con la letra asignada, haciendo uso de un dispositivo móvil. Posteriormente, resolvieron un test de comprensión literal de 10 preguntas y cada respuesta acertada tenía un valor de 0.5 .

Por otra parte, en las últimas siete sesiones se realizaron los pasos dos y tres, con el grupo de combinaciones PR- PL, TL- TR, DR, FR- FL, CR- CL, BR $B L, G R-G L$, con el fin de afianzar la fluidez verbal y comprensión lectora. EL trabajo con estos REA tuvo una duración de dos horas, ya que cada paso equivale a una hora.

\section{(b) Instrumentos.}

En el transcurso de la fase de implementación, se utilizó el instrumento de evaluación embebido en los REA (Valoración de desempeño en porcentaje en los LIM del abecedario 2.0 y valoración de desempeño de 0.0 a 5.0 en los Test de comprensión literal 2.0), para recolectar el desempeño estudiantil con las tecnologías.

La meta prevista era alcanzar el $50 \%$ de desempeño en los LIM del abecedario 2.0, donde el mínimo de aprobación se obtenía con el 30\% equivalente a 3.0. En los Test de comprensión literal 2.0 fueron calificados en una escala de cero a cinco, donde 0.0 era la mínima nota y 5.0 la máxima, siendo la nota límite 
de aprobación para cada test de 3.0; ya que esto significa que resolvió correctamente la mitad más una, es decir, seis preguntas de 10 posibles.

\section{(c) Resultados.}

En esta subsección, se presenta la validación de los REA que fueron creados para apoyar el nivel intratextual de la comprensión lectora en el grado primero. Aquí se detallan los desempeños generales, mediante la tabulación de la información recolectada, el análisis de los datos y la interpretación de los resultados en las dos instituciones educativas.

Como se mencionó anteriormente, Ios REA se implementaron en las Instituciones Educativas H.D. de Puerto Triunfo y F.R.S. de Maceo en Antioquia, Colombia, obteniendo los siguientes resultados por establecimiento educativo.

Los desempeños de los estudiantes en los LIM del abecedario 2.0 en la Institución Educativa H.D. son los siguientes:

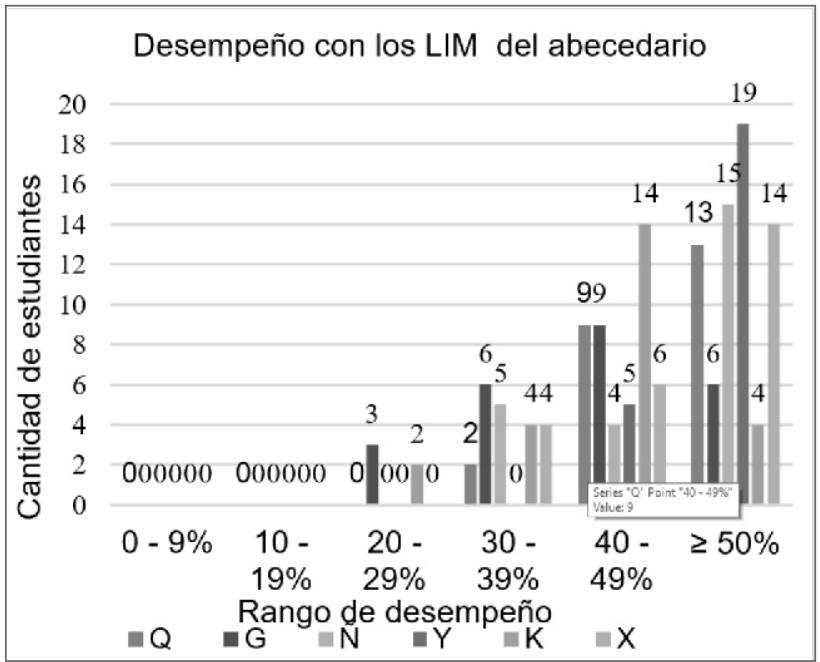

Figura 3. Desempeño LIM del abecedario 2.0 en la IER H.D.
En la Figura 3, se observa que durante la implementación, la mayoría de los estudiante aprobó el rango límite y que solamente cinco educandos reprobaron en total en los LIM G y K, en el rango del 20 al $29 \%$.

En general, se deduce que el $96,5 \%$ de los estudiantes obtuvo un buen promedio de desempeño con los LIM del abecedario 2.0 y que solamente el $3,5 \%$ está en el rango del 20 al $29 \%$.

Durante la implementación de los LIM del abecedario 2.0, fue estratégico realizar recomendaciones sobre el uso de los equipos tecnológicos y del trabajo colaborativo.

Adicionalmente, en algunas ocasiones se intercambiaron niños entre los grupos con el fin de aumentar su participación y rendimiento del equipo, ya que no demostraban interés, no trabajaban en equipo y/o generaban desorden.

En general se observó una mejora en el comportamiento, la motivación y el trabajo colaborativo en los estudiantes que buscaban obtener un buen resultado. También que disfrutaron con las animaciones, locuciones, sonidos y colores para resolver cada una de las actividades interactivas.

Se observa, que en general se apoyó a través del uso de los REA, el nivel de lectura a partir de la semántica y la sintaxis. Muchos de los niños lograron obtener autonomía para resolver las actividades de construcción de conocimiento, sin la asesoría del docente, ya que los LIM ofrecían información asociada (gráfica, textual y auditiva).

Los desempeños de los estudiantes en los LIM del abecedario 2.0 en la Institución Educativa Filiberto Restrepo Sierra se muestran en la figura 4. 


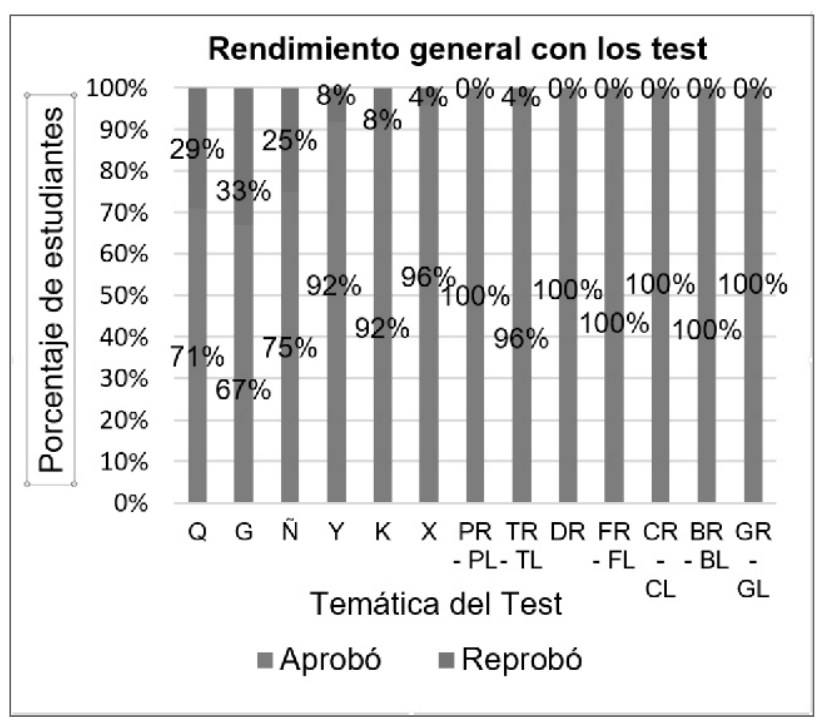

Figura 4. Desempeño LIM del abecedario 2.0 en la IE F.R.S.

De la figura 4, se concluye que durante la implementación de los LIM del abecedario 2.0, en promedio, el $62,8 \%$ de los estudiantes tiene un desempeño mayor o igual a 50\%, el $10 \%$ está en el rango del 40 al $49 \%$, el 6,1\% está en el rango de 30 al $39 \%$; que el 2,2\% está en el rango del 20 al 29\%, el $17,8 \%$ está en el rango del 10 al $19 \%$ y el $1,1 \%$ está en el rango de 0 al $9 \%$.

En otras palabras, el 78,9\% aprobó los LIM del abecedario 2.0 y el $21,1 \%$ no alcanzó el límite de aprobación.

Las razones de este resultado radican en que presentan dificultades para decodificar y esto obstaculiza que resuelvan las actividades de construcción de conocimiento.

En general, fue novedoso para los estudiantes encontrar palabras nuevas en las diferentes actividades interactivas, lo cual fue positivo pero a la vez dificultó el proceso de asimilación, ya que no asociaban el signo lingüístico.
Fue clave formar subgrupos para el desarrollo de las actividades, debido a que facilitó entre los niños el aprendizaje colaborativo, donde la ayuda mutua permitió alcanzar mayores resultados.

Es de mencionar, que el uso de los LIM del abecedario 2.0 con las consonantes implementadas, cautivó el interés y la motivación en los estudiantes.

Adicionalmente, la propuesta didáctica que presentó diversidad de actividades acompañadas de gráficos, textos y audio, fortaleció el proceso lector de los estudiantes, aumentó el vocabulario y les brindó una experiencia con mayores aprendizajes autónomos para apoyar la comprensión lectora.

Los desempeños de los estudiantes en los Test de comprensión literal 1.0 y 2.0 en la Institución Educativa Hermano Daniel se muestra en la figura 5.

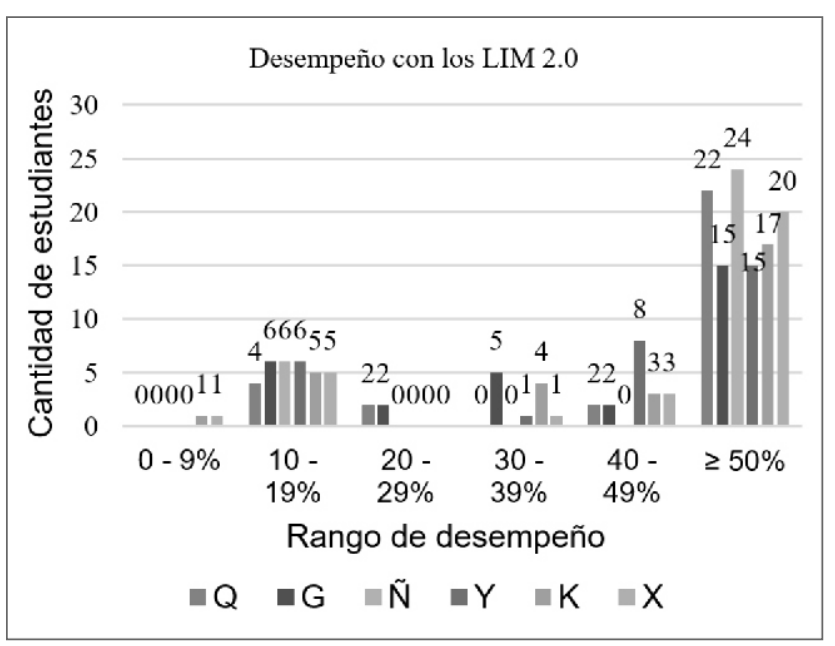

Figura 5. Rendimiento Test de comprensión literal en la IE H.D.

En la figura 5, se observa que durante el Test Q, más de las dos terceras partes $(70,8 \%)$ aprobó y menos de una tercera parte $(29,2 \%)$ reprobó; en el Test $G$ dos terceras partes $(66,7 \%)$ aprobó y una tercera parte $(33,3 \%)$ reprobó; en el Test Ñ tres cuartas partes (75\%) aprobó y una cuarta parte (25\%) reprobó. 
En los Test Y y $\mathrm{K}$ la mayoría $(91,7 \%)$ aprobó y una mínima (8,3\%) parte reprobó; en los Test X y TR - TL aprobó la mayoría con el 95,8\% y reprobó una parte mínima con el 4,2\%.

En cuanto a los Test PR - PL, DR, FR - FL, CR - CL, BR BL y $G R-G L$, aprobó el $100 \%$, es decir, en seis test de trece posibles se obtuvo un rendimiento completo.

Concluimos que inició reprobando hasta una tercera parte y poco a poco se fue reduciendo esta cantidad hasta terminar en que todos aprobaron los últimos test. Esto podría indicar que se mejoró el nivel de lectura y de comprensión lectora en la mayoría de los educandos.

Adicionalmente a lo presentado, se realizó lectura en voz alta, guiada y compartida para resolver los test con algunos estudiantes.

Sin duda alguna, fue sorprendente encontrar que no necesariamente quien sabe leer comprende lo que lee, ya que en algunos casos se encontraron estudiantes que a pesar de tener dificultades lectoras, era posible que comprendieran o viceversa.

Por otro lado, se logró motivar a todos los educandos durante el proceso, se evidenció el interés por participar de las actividades previas e interactivas.

En cuanto al comportamiento, se afirma que si la dinámica implementada por el docente en el aula fue llamativa, el grupo va a demostrar actitudes muy favorables.

En general, el rendimiento académico y disciplinario del grupo dio grandes resultados durante la implementación de la propuesta investigativa.

Los desempeños de los estudiantes en los Test de comprensión literal 1.0 y 2.0 en la Institución Educativa Filiberto Restrepo Sierra se muestran en la figura 6.

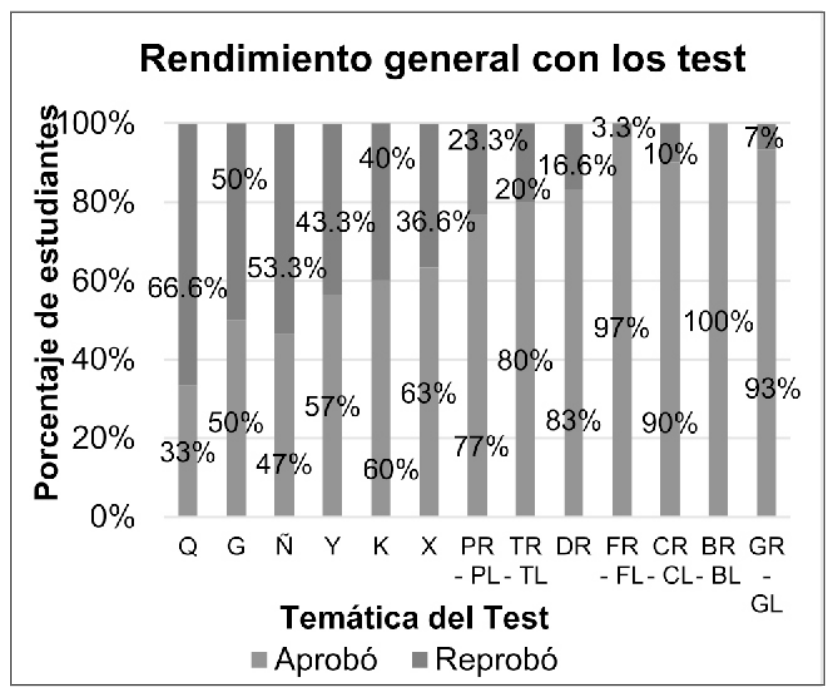

Figura 6. Rendimiento Test de comprensión literal en la I.

E.

En la Fig. 6. se observa que durante el test $Q$ de comprensión literal 1.0, la tercera parte $(33,3 \%)$ aprobó y dos terceras partes $(66,6 \%)$ reprobaron; en el test $\mathrm{G}$ de comprensión literal 1.0, la mitad (50\%) de los estudiantes aprobó y la otra mitad, (50\%) reprobó.

En el test $\tilde{N}$ de comprensión literal 1.0, casi la mitad $(46,6 \%)$ aprobó y más de la mitad $(53,3 \%)$ reprobó; en el test $Y$ de comprensión literal 1.0, más de la mitad $(56,6 \%)$ aprobó y menos de la mitad $(43,3 \%)$ reprobó.

En el test $\mathrm{K}$ de comprensión literal 1.0, tres quintas partes (60\%) aprobó y dos quintas partes (40\%) reprobó; en el test $X$ de comprensión literal 1.0, casi dos terceras partes (63.3\%) aprobó y más de una tercera parte $(36,6 \%)$ del grupo reprobó.

En el test PR-PL de comprensión literal 2.0, más de tres cuartas partes $(76,6 \%)$ aprobó y menos de una cuarta parte $(23,3 \%)$ reprobó; en el test TR-TL de comprensión literal 2.0, cuatro quintas partes (80\%) aprobaron y una quinta parte reprobó; en el test DR de comprensión literal 2.0, más de cuatro quintas partes $(83,3 \%)$ aprobó y una sexta parte $(16,6 \%)$ reprobó. 
En el test FR-FL de comprensión literal 2.0, aprobó la mayoría con el $96,6 \%$ y reprobó una mínima parte con el 3,3\%; en el test CR-CL de comprensión literal 2.0, la mayoría aprobó $(90 \%)$ y una décima parte $(10 \%)$ reprobó.

En el test BR-BL de comprensión literal 2.0, aprobó el $100 \%$ y finalmente en el test GR-GL de comprensión literal 2.0, la mayoría aprobó (93 \%) y solo una mínima parte $(6,6 \%)$ reprobó.

Los resultados que se muestran en la figura 6, reflejan cómo inicialmente reprobó más del 50\%, y cómo fueron avanzando los estudiantes durante la línea de tiempo de la implementación, reduciéndose la cifra de reprobación.

Aunque solo un test fue aprobado en un $100 \%$, se evidencia la manera en que poco a poco fue mejorando el nivel de comprensión lectora en la mayoría de los estudiantes; sin duda alguna, el apoyo de la docente con aquellos estudiantes fue esencial para alcanzar estos logros.

Durante la intervención, se evidenció que los niños trabajaron motivados en cada una de las actividades de construcción de conocimiento.

Así mismo, se observó en los estudiantes que aprobaron los test de comprensión literal 1.0 y 2.0, que avanzaron en su proceso de decodificación y comprensión, pues reconocían con facilidad palabras y frases asignándole su correspondiente significado, gracias a los ejercicios desarrolladas en LIM del abecedario 2.0; que permitieron ampliar su vocabulario. De igual forma, demostraron habilidad para recordar detalles y escenas en cada uno de los textos, siguiendo las secuencias ordenadas de los mismos.

El trabajo con los dispositivos móviles impactó a los estudiantes, debido a que algunos solo lo utilizaban para jugar y otros no habían tenido la experiencia de manipularlos, de esta manera, se logró mantener siempre el interés de los niños, quienes poco a poco se fueron convirtiendo en responsables de su aprendizaje. Es decir, autoaprendizaje, pues sin importar sus dificultades, siempre querían intentarlo una y otra vez para practicar lectura y recuperar información explícita en el texto.

\section{DISCUSIÓN}

Este trabajo de investigación conduce hacia una reflexión del impacto de los REA en los procesos de comprensión lectora de los estudiantes.

Durante el ejercicio de implementación, se observaron cambios favorables respecto a las etapas logográfica y alfabética, demostrando inicialmente habilidad para reconocer palabras y frases, relacionar imágenes con su correspondiente significado, establecer correspondencia entre los fonemas que forman una palabra y las grafías necesarias para escribirla, fundamentando el proceso de adquisición y/o desarrollo de las habilidades comunicativas a partir del signo lingüístico, es decir, entre el significado, el significante y el referente.

Las actividades multimedia con los LIM del abecedario 2.0 fueron pieza clave para que los estudiantes comprendieran y formaran oraciones, ampliaran su vocabulario y potenciaran su percepción visual, es decir, como refuerzo al proceso lector e introducción a la comprensión lectora en su nivel literal. Además, posibilitaron la creación de un entorno de aprendizaje interactivo, dinámico, colaborativo y autónomo.

En los test de comprensión literal 1.0 y 2.0, los resultados indican que los estudiantes tuvieron capacidades para recuperar información explícita como: reconocer detalles, nombres, hechos, lugares y personajes de los textos.

Es de resaltar que el grupo de la Institución Educativa F.R.S., al inicio de la implementación, desconocía el 
lenguaje simbólico empleado en los LIM, carecían de saberes frente al manejo de las TIC, ya que la docente no empleaba estos recursos. Esta intervención abrió las puertas al uso de nuevas tecnologías en la institución, brindando a los estudiantes mayor diversidad de estrategias para el aprendizaje.

Es de anotar, que el grupo de estudiantes de la IER H.D. obtuvo mayores resultados en la implementación, mayor interés por la lectura empleando las tecnologías, porque se encontraban más familiarizados con las TAC, debido a que el docente de esta institución hacía uso regular de ellas en el aula.

El ambiente de aprendizaje mediado por TAC contribuyó al disfrute de las lecturas y actividades por parte de los educandos, enriqueciendo sus conocimientos y ampliando su vocabulario en forma notable; además de mejorar la motricidad fina manipulando el computador o dispositivo móvil e identificar algunas funciones básicas de los mismos.

Es de resaltar la importancia de las TAC en las prácticas pedagógicas, pues con ellas se pueden desarrollar clases más activas y dinámicas.

Con los REA (LIM del abecedario 2.0 y test de comprensión literal 1.0 y 2.0) se afianzó el proceso de aprendizaje de la lectura y la comprensión lectora, a partir de la generación de un ambiente de aprendizaje que motivó lúdicamente a los educandos, confirmando de esta manera la afirmación El niño no juega para aprender pero aprende cuando juega (MEN 2013).

Las TAC en el aula contribuyeron de manera directa en los procesos aprendizaje y es deber de los docentes usarlas metodológicamente en sus prácticas pedagógicas, siempre y cuando sea de manera didáctica, de lo contrario, solo se estaría cambiando de herramienta (tablero por tecnología).

\section{CONCLUSIONES}

Desarrollar REA utilizando diferentes tipos de tecnologías para apoyar el nivel intratextual de la comprensión lectora en los estudiantes del grado primero " $A$ ", es una solución prometedora y ha sido evidenciado en este trabajo de investigación.

La metodología seguida permitió obtener resultados favorables con la población objeto.

El diagnóstico de las necesidades educativas de los estudiantes, el diseño de los REA teniendo en cuenta las necesidades y preferencias de la población, el desarrollo de los REA considerando la diversidad de estudiantes, y su respectiva evaluación en las Instituciones Educativa H.D. y F.R.S., durante el segundo semestre del año 2015, permitió apoyar a los estudiantes en el logro del nivel intratextual de la comprensión lectora.

En la Institución Educativa H.D. aprobó en promedio el 100\% (24 estudiantes) con los LIM del abecedario 2.0, los cuales permitieron afianzar la lectura e introducir a los estudiantes a la comprensión literal. Por otro lado, el 95,83\% (23 estudiantes) aprobó en promedio los test de comprensión literal 1.0 y 2.0 para apoyar la comprensión lectora.

Por otro lado, en la Institución Educativa F.R.S. aprobó en promedio el 80\% (24 estudiantes) con los LIM del abecedario 2.0 y con los test de comprensión literal 1.0 y 2.0; siendo esta experiencia, la primera vez que los estudiantes usan REA, lo que fue para ellos muy significativo obteniendo resultados valiosos y prometedores.

En general, al sumar los estudiantes de las dos instituciones educativas, se obtiene como total 54 estudiantes (equivalentes al $100 \%$ ), de los cuales, aprobaron $47(87,03 \%)$ y reprobaron 7 estudiantes $(12,96 \%)$. 
En los informes del primer periodo académico de ambas instituciones, se muestra que el $21 \%$ de los estudiantes reprobó el área de lenguaje y en el period, solo reprobó el 12,96\%.

Los resultados de esta investigación concluyen que se logró reducir la tasa de reprobación del área de lenguaje significativamente.

TRABAJO FUTURO Se pretende extender la experiencia del uso de las tecnologías desarrolladas durante un año y medio en ambas instituciones educativas siguiendo la metodología diseñada.

AGRADECIMIENTOS Los autores F.A. y S.B. Ie agradecemos a Dios por brindarnos vida, sabiduría, disciplina y fortaleza para hacer realidad el sueño de ser Magister. A la doctora Silvia Margarita Baldiris Navarro, por su enseñanza, paciencia, compromiso y responsabilidad, que hicieron posible construir el proyecto investigativo y este artículo. A nuestras familias por apoyarnos incondicionalmente, por su paciencia y creer en nosotros.

\section{REFERENCIAS}

Aliaga, F., y Bartolomé, A. (2006). El impacto de las nuevastecnologías en educación. Investigación en innovación educativa: algunos ámbitos relevantes. Universidad de Valencia y Universidad de Barcelona. Recuperado de:

http://www.uv.es/aliaga/curriculum/Aliaga\&Bartolo me-2005-borrador.pdf

Caamaño, A.; y González, M. (2012). La lectura y su relaciónconelconocimiento y el aprendizaje. México: Universidad Autónoma Metropolitana. Recuperado de:

http://zaloamati.azc.uam.mx/bitstream/handle/1119 1/2112/La_lectura_44_06.pdf?sequence=1

Calzadilla, M. (2002). Aprendizaje colaborativo y tecnologías dela informacióny la comunicación. Iberoamericana de educación, 1(10), 1-10. Recuperado de:

http://webs.ono.com/jorgeperez67/Webquest_Tem a13/docs/APRENDIZAJE\%20COLABORATIVO\%20y\%2 Otic.pdf

Cantillo, C., Roura, M. y Sánchez, A. (2012). Tendencias actualeseneluso de dispositivos móviles en educación.La Educ@ción Digital Magazine,147(1),121. Recuperado de:

http://www.educoas.org/portal/la_educacion_digital /147/pdf/ART_UNNED_EN.pdf

Hernández, J. \& Arteaga, D. (2011). Las TIC como facilitadoras en la comprensión lectora. Universidad Católica de Pereira. Recuperado de: http://ribuc.ucp.edu.co:8080/jspui/bitstream/handle /10785/580/completo.pdf?sequence=1\%20http://w ww.feandalucia.ccoo.es/docu/p5sd5948.pdf

Londoño, L. (2011). Investigación y desarrollo de aplicaciones sobre sistema operativo Android. Universidad Católica de Pereira. http://ribuc.ucp.edu.co:8080/jspui/bitstream/handle 


\section{. . F."Ingenierías}

/10785/2999/CDPEIST69.pdf?sequence=1

Macías, F. (2006). Libros Interactivos Multimedia. LIM. Educalim. Recuperado de :

http://www.educalim.com/cinicio.htm Consultado el 25 de mayo 2016.

Martínez, R. y Alonso, J. (2014). Investigación Educativa en Educación Primaria. Tesis de doctorado. España: Universidad de Murcia. Recuperado de: libros.um.es/editum/catalog/view/1151/1821/14211

MEN. (2013). Actividades rectoras de la primera infanciaydela educación inicial. Primera infancia: Educación inicial. Recuperado de http://www.mineducacion.gov.co/primerainfancia/1 739/w3-article- 178032.html Consultado el 25 mayo 2016.

MEN. (1998). Serie lineamientos curriculares: Lengua castellana. Bogotá: Cooperativa Editorial Magisterio. Recuperado de:

http://www.mineducacion.gov.co/1621/articles339975_recurso_6.pdf
Paredes, C. (2013). Uso de Dispositivos Móviles en Educación. Realidad Aumentada. Tesis de Máster. Valladolid: Universidad de Valladolid. Recuperado de: http://uvadoc.uva.es/handle/10324/3410

Pastor, C. (2012). Aportaciones del Diseño Universal para el Aprendizaje y de los materiales digitales en el logro de una enseñanza accesible. Madrid: Universidad Complutense de Madrid. Recuperado de: http://diversidad.murciaeduca.es/publicaciones/dea 2012/docs/calba.pdf

Tabares, A., Garcés, D. y Gómez, Y. (2013). Comprensión lectora en el niño, cuestión de ingenio: Las Tecnologías de la Comunicación y la Información para el fortalecimiento de los procesos de comprensión lectora. Medellín: Universidad de San Buenaventura. Recuperado de:

http://bibliotecadigital.usbcali.edu.co:8080/jspui/ha ndle/10819/1215

Unesco, (2015). Guía básica de Recursos Educativos Abiertos (REA). Recuperado de:

http://unesdoc.unesco.org/images/0023/002329/23 2986s.pdf 